\title{
Almost Human
}

Link to publication record in Manchester Research Explorer

\section{Citation for published version (APA):}

Balmer, A. S., \& Goulden, M. (2009). Almost Human: Scientific and Popular Strategies for Making Sense of "Missing Links". In S. B., H. J., \& A. W. (Eds.), Contested Categories: Studies of the Life Sciences in Society Ashgate Publishing .

http://www.academia.edu/158882/Almost_Human_Scientific_and_Popular_Strategies_for_Making_Sense_of_Miss ing_Links_

\section{Published in:}

Contested Categories: Studies of the Life Sciences in Society

\section{Citing this paper}

Please note that where the full-text provided on Manchester Research Explorer is the Author Accepted Manuscript or Proof version this may differ from the final Published version. If citing, it is advised that you check and use the publisher's definitive version.

\section{General rights}

Copyright and moral rights for the publications made accessible in the Research Explorer are retained by the authors and/or other copyright owners and it is a condition of accessing publications that users recognise and abide by the legal requirements associated with these rights.

\section{Takedown policy}

If you believe that this document breaches copyright please refer to the University of Manchester's Takedown Procedures [http://man.ac.uk/04Y6Bo] or contact uml.scholarlycommunications@manchester.ac.uk providing relevant details, so we can investigate your claim.

\section{OPEN ACCESS}




\section{Almost Human: Scientific and Popular Strategies for Making Sense of “Missing Links"}

Goulden, M \& Balmer, A.S.

Within western culture there exists a rigid distinction between animal and human, a distinction sustained by the Judeo-Christian tradition (Thomas 1996:1725) and by eminent philosophers including Aristotle and Descartes. 'Man', created in the image of God and possessor of a soul, language, and culture, stands clearly distinct from all other animals, senseless and soulless as they are. Such a binary continues to dominate the popular taxonomy, despite the emergence and development of radical evidence to the contrary from the life sciences. One such example is palaeoanthropology, which has troubled this polarisation of animal life, introducing multiple species to the imagined point of departure from animals, turning the human phylogenetic tree into a veritable bush. Our principle concern is with "missing links", those figures deemed to fall somewhere between the categories animal and human. It is these fossils that should undermine the dichotomy but that have somehow, within the popular conception, been made to serve it. Two famous examples will be drawn upon, Piltdown Man and Homo floresiensis, as we study how these liminal figures are reconciled with the dichotomous model that popular culture holds, and what shapes their journey from science to the public. 
This book's focus is life sciences, which may ordinarily be thought to exclude a science far removed from popular images of the cutting edge laboratory work seen in fields like genomics. However, palaeoanthropology, the scientific study of early humans using fossil evidence, is just as concerned with 'life' as any biological, laboratory-based investigation of living organisms. In fact, it is the very origins of human life, the question of how we came to be the way we are, to which palaeoanthropologists apply themselves. More specifically, this book examines life science categories with regard to science-culture interactions. In this respect, palaeoanthropology is a field much overlooked by the social sciences, which is regrettable given the huge media attention its discoveries can receive. In the case of Homo floresiensis:

When the discovery was announced all hell broke loose, as the world's media e-mailed and phoned our offices and homes - about 200 inquiries a day for the first week, with Peter doing 100 interviews in the first three days. The interest was overwhelming: we were featured in about 98,000 websites and were headlined in about 7,000 newspapers. (Morwood \& van Oosterzee 2007:186)

\section{Introducing Piltdown Man and Homo floresiensis}

The discovery of Piltdown Man in the gravel pits of East Sussex in 1912, by a team led by prominent British scientist A.S. Woodward and amateur geologist Charles Dawson, has become something of a cultural mystery story. 
Indeed, it has the dubious honour of being perhaps the greatest hoax in scientific history and remains mysterious as the identity of the perpetrator(s) is still disputed. Like other "missing links" Piltdown awoke in a purgatory somewhere between animal and human. It embodied both with its large human-like cranium and ape-like jaw but fit solely in neither one. It was not until four decades later, in 1953, that the creature was found to be a fake: no more than the juxtaposition of a modern human skull and orangutan jaw. The constituent parts had been stained to feign age and the teeth filed to appear human. That the creature was found to be a hoax is of no great concern to us here, however, since it is the immediate reception of it as a missing link that provides our focus.

Homo Floresiensis, by contrast, was discovered on Flores - one of the larger islands of the chain that makes up Indonesia - in 2003. The site from which the type specimen was removed, known as Liang Bua, gave the figure its name LB1. The specimen was most remarkable for its short stature and small brain, and was announced to the world at joint conferences in London and Sydney on the $27^{\text {th }}$ October 2004. The events were hosted by the journal Nature, which carried two papers on the find in its issue released the following day. The discovery received huge attention from the world's media, as the quote in our introduction attests.

The purpose of this chapter is to study the means by which scientifically categorised knowledge (i.e. missing links) is made sense of in the public realm. 
We chart this process through the use of two concepts that originate in Serge Moscovici's study on the adoption of psychoanalysis in France (Moscovici, S. 1961). Moscovici identified processes by which unfamiliar knowledge becomes familiar through 'social representations'. His exposition on this process as regards scientific knowledge is particularly prescient for our present concern:

One often hears that a good science should begin by proposing clear and carefully defined concepts. Actually, no science, not even the most exact, proceeds in this way. It begins by assembling, ordering, and distinguishing phenomena which surprise everyone, because they are disturbing, or exotic, or create a scandal (1998:209).

The ordering of the ontologically disturbing and geo-temporally exotic phenomena of missing links occurs via the strategies of 'anchoring' and ‘objectifying', which Lievrouw (1990) explicates thus:

Representations [of scientific knowledge claims] are generated by a dual process of anchoring (classifying an unfamiliar phenomenon into a set of categories) and objectifying (converting the unfamiliar and abstract phenomenon into a familiar and concrete phenomenon by developing an image of it) (p.5). 
The translation of these objects, or categories, in this book's parlance, involves the movement from realm to realm and requires a reconfiguration of their categorisation, as they have to be made sense of by a different audience with a considerably different conceptual framework. For Piltdown and LB1 this takes the form of a journey from 'Homo' to 'human'. In the present study, anchoring refers to the process by which missing links are made to fit within the animal - human binary of popular culture. We shall see that this primarily involved declaring these finds, despite their contradictory features, 'human’. Here, objectifying concerns the creation, around the figures, of narratives that act to cement their conceptually unstable status. This, we shall see, took the form of stories demonstrating these figures’ humanness. It is why these figures became human, and how they were made human, that will reveal the interactions that take place between science and non-science culture when scientists investigate life.

\section{Becoming Homo}

Before exploring these processes empirically, it will be instructive to consider the scientific category 'Homo', as it involves the self-interested role we Homo sapiens play in the process of creating taxonomic order from nature's disorder, which rests at the heart of this chapter. Moreover, it lies at the heart of modernity, for it is only our conceptually strict division of nature and culture that allows the two to be mixed so readily in practice (Latour 1993). 
The genus Homo was created by the father of scientific taxonomy, Carl Linnaeus, to mean 'man', whilst the species name sapiens was chosen to signify 'wise'. In a forerunner of later uncertainty we, as Homo sapiens, were not alone in this genus, but joined by Homo troglodytes ('cave-dweller'), which comprised anthropomorphic apes of which Linnaeus had received reports (Marks 2003:21). Now known as chimpanzees, these animals have long since been removed from Homo to their own genus, Pan, but the source of Linnaeus' confusion - the combination of similarity and difference that marks our ontological relationship with both extant non-human primates and extinct missing links - remains all too evident. The personal stake we hold in this relationship leads Donna Haraway to state that "western primatology has been about the construction of the self from the raw material of the other, the appropriation of nature in the production of culture” (1989:11). Whilst most evident in our dealings with our closet ancestors, this may extend to all animal life (Daston \& Mitman 2005; Franklin 1999).

These problems are not unique to Homo sapiens and their phylogenetic relatives, since all attempts to categorise nature, as scientific taxonomy does, face the problem of a disjuncture between the ruler-straight demarcations of classification, and the ebbs and flows of the natural world. Species are not biological 'natural kinds', as the units of evolution are individuals, not groups. It is for this reason that Dupre argues against 
the picture of evolutionary change flowing down sharply defined channels, branching at well-defined nodes... A more realistic picture would be a river estuary at low tide. We find large streams of water and many side streams, some petering out, others rejoining a main channel or crossing into a different channel, and a few maintaining their integrity to the ocean; there are islands around which streams flow and then rejoin; eddies and vortices; and so on (2001:207).

Despite what is implied to the uninitiated by the clean lines of taxonomic charts, there is no missing link between any two species, but rather innumerable missing links. The act of taxonomy, however, shrinks all these links down to the width of a single line. In the face of similarity and difference, the decision as to what goes on which side of the line often relies as much on value judgments as it does on empirical evidence.

Even those tangible divisions that separate contemporaneous, analogous species, such as reproductive incompatibility, disappear once viewed from the perspective of evolutionary history, a perspective which the missing link demands. Here all species are interconnected through an unbroken chain of progenitor and descendant. When you add in to this mix the self-interested role that modern Homo sapiens hold when drawing lines separating or joining ourselves and our evolutionary relatives, it is unsurprising that the categorisation of missing links as Homo, human, or neither, can become highly contested. 


\section{Anchoring Missing Links}

Piltdown Man was received as a sensation in the English scientific media and press, both of which quickly proclaimed him to be an English find to match those of imperial rivals Germany (Homo neanderthalensis) and France (Dryopithecus fontani $)^{1}$. The discrepancy between the skull and jaw size went almost without exception - unchallenged in the UK, which is telling of the national pride that came to influence Piltdown's human character.

Notably, Piltdown's categorisation as human by English scientists is in evidence right from the beginning. The presentation of the find on the $18^{\text {th }}$ December 1912 at a meeting of the Geological Society was made under a title proclaiming: “On the Discovery of a Paleolithic Human Skull and Mandible in Flint-Bearing Gravel Overlying the Wealden (Hastings Beds) at Piltdown, Fletching (Sussex)” (Dawson \& Woodward 1913). Dawson refers to an "unusually thick human parietal bone” (ibid:117) and "the right half of a human mandible” (ibid:121), assertions of humanness that are also made by Woodward (ibid:124). The ambiguity of the find is raised though it doesn't appear to challenge the humanness of the specimen in any significant fashion: "The great width of the temporal insertion, the situation of the mylohyoid groove behind rather than in line with the dental foramen... are all characters of the mandible in apes, not in man” (ibid:131). Woodward went so far as to place the find in an

\footnotetext{
${ }^{1}$ Remains of Dryopithecus fontani and Homo Neanderthalensis were discovered in France and Germany respectively in 1856, and as such were the first recognized hominan discoveries.
} 
entirely new genus - Eoanthropus ('Dawn Man') - in recognition of the unusual character of the jaw (ibid:135) and awarded the species name Dawsoni in honour of its discoverer. The result was that humanness was applied outside our own genus Homo. Despite its contradictions, which they acknowledge in its scientific classification, Dawson and Woodward used their considerable authority as scientists to categorise this missing link as human. Why, if this creature's physical remains were so contradictory, was it claimed as human by scientists, rather than ‘ape'? Why, indeed, did scientists use 'human' at all when it would be safer to stick to scientific categorisations?

The answer is twofold. Firstly, anthropocentricism meant that Piltdown the 'backwards human' was far more salacious a story than Piltdown the 'forward ape’ (Express 12.08.13:1). The desire among scientists to grab the news media’s and hence the public's - attention was as important as any scientific evidence in the decision to declare Piltdown human. This same pressure encouraged the use of human rather than sticking to a more esoteric, but defensible, scientific categorisation.

The English press repeated the process of forcing Piltdown to fit into the human side of the binary, even whilst acknowledging its contradictions:

a new race of men, in points strongly resembling the apes, but still unquestionably "man”, although devoid of the power of speech. (Express 20.12.12:1) 
the oldest human remains yet discovered in Europe... a being that is partly ape, partly man. (Times 11.08.13:3)

Second, driving Piltdown toward humanness was a strong nationalistic desire to proclaim the find significant enough to rival those made already in mainland Europe. The original Guardian report states the find is "quite as early as anything that has been found in Europe" (21.11.12:8) and later declares "it is extremely satisfactory to English scientists that this find should have been made here and that it should have been made by two well-known English geologists" (20.12.12:16). Following this theme, the Illustrated London News refers to "this Ancient Briton” (28.12.12:958) and Woodward's own memoir of Piltdown, published only five years before the hoax was unmasked, is entitled The Earliest Englishman (1948). In the discussion section of a follow-up paper, a tool found with the remains is referred to as being that most quintessential of the English gentleman’s trappings: a “cricket-bat” (Dawson and Woodward 1915:148). Whilst the find was overwhelmingly supported as human in the UK, the reception in Europe and America was far more mixed. American palaeoanthropologists Miller (1915, 1918), MacCurdy (1916) and Hrdlicka (1922) all doubted that the find was a single individual (Goulden in press).

It is clear then that anthropocentricism and nationalism both influenced the manner in which Piltdown was anchored in relation to the human-animal binary 
within the public realm. The influence of anthropocentricism is similarly visible, almost a century later, in the case of Homo floresiensis, to which we now turn.

One of the principle scientists in the Flores find, Mike Morwood, showed his awareness of problems brought by blurring scientific and popular categories during anchoring: in his account of the discovery, he states “The definition of genus Homo has always been difficult because it is closely tied to the concept of “being human”,” (Morwood \& van Oosterzee 2007:97). The conflating of Homo and human only makes the task of categorising the former even more difficult than taxonomy is ordinarily. The former is a scientific category, clearly (though, as we shall see, flexibly) defined, separated from common language not only by its history and usage but also by its capitalisation and italicisation. 'Human' has no such isolating elements however. As a word and as a concept it is very much a part of both popular culture and of self-perception. As a result it often finds itself tied to other concepts relating to the Self, hence the prominent influence of racism in Piltdown man's journey towards humanness, which we discuss below. Additionally, using Homo and human interchangeably means that as many as seven other species ${ }^{2}$, all now extinct, were human too. Popular culture, however, has only ever applied 'human' to one living species - ourselves - and it is what we are, in whatever way we are contemporaneously formulated, which determines

\footnotetext{
${ }^{2}$ As this chapter implies, there is no clear scientific consensus on the number of species within the genus Homo, but some list as many as eight $-H$. ergaster, $H$. erectus, $H$. habilis, $H$. heidelbergensis, H. neanderthalensis, H. rudolfensis, H. sapiens (Woods \& Collard 1999), plus newly discovered $H$. floresiensis.
} 
its characteristics. One must question then whether the extension of humanness to other species is semantically coherent. Morwood cites floresiensis' ability to use fire and basic stone tools as reason for its declared humanity, but at the same time acknowledges that it lacked several key human characteristics:

[not] the least hint of symbolic behaviour, such as pigments, art, adornments or formal disposal of the dead, which are core characteristics of all modern human cultures. (2007:114)

Morwood's keenness to label LB1 human returns us to the anthropocentrism which makes discoveries of 'backwards humans' bigger news than discoveries of 'forward apes'. This attitude encourages both scientists and journalists alike to categorise a find not just as 'Homo', but also as the more emotive, the more personal, 'human'. It quite literally gives a discovery more 'human interest'. Certainly, Piltdown as a human fitted well with “media news values such as meaningfulness and relevance to daily life” (Cassidy 2005:136). The recollections of Australian science journalist Deborah Smith, who won a Eureka Science Prize for her coverage of Homo floresiensis, hints at this too with her usage of the label 'person':

I can remember the look on my editors face when I went up and said 'now I’ve got a very good front page story here, its about a little person, they 
hunted pygmy elephants, giant rats, they lived on Australia's doorstep until 12,000 years ago, they fended off Komodo dragons, they've been found by Australians, and we got all this fantastic graphic material', and she just looked at me and said 'Deborah, this story has everything' (2007. our italics).

The mixing of the categories of Homo and human not only intensifies our self-interest in who, or what, it includes and excludes, but also leaves scientists attempting to find physical evidence of an intangible concept - what makes a human human? In their original submission to Nature, the team that discovered LB1 placed her within a new genus, Sundanthropus, meaning 'man from the Sunda region'. Morwood was desperate to label the find Homo, stating that:

Selecting the right name for the species was important scientifically and politically, to ensure that LB1 was not regarded as just some Southeast Asian oddity of little relevance to the understanding of hominid evolution and dispersal generally (Morwood \& van Oosterzee 2007:100-101).

However, fellow scientist and team member Peter Brown refused on the grounds that its skull capacity, at 380 cc, was significantly below the 'Cerebral Rubicon' of 600 c.c., considered mandatory for inclusion in the genus Homo (Woods \& Collard 1999). The 'Cerebral Rubicon' is demonstrative of the difficulties 
scientists face in attempting to attribute humanness on the basis of limited physical evidence in that it requires a reifying of humanness. Prominent Piltdown scientist Sir Arthur Keith had set this at 750 c.c. (1949), whilst Franz Weidenreich declared it to be 700 c.c. (1943), at least in part because this ensured his discovery, Pithecanthropus, was on the human side (Krantz 1961:86). In the 1960s, the discovery of the smaller brained Homo habilis by Louis Leakey (1964) led him to lower the bar further, down to 600 c.c. This is the figure that Wood and Collard cite in their influential ${ }^{3}$ (pre-Flores) paper, which Brown used to justify LB1's status outside Homo. Morwood's response to this highlights the flaw in the idea that we can determine humanness on the basis of a specific brain capacity:

But should size matter? I thought. Surely, it is more a question of cognitive capabilities - and there was abundant evidence that the Liang Bua hominids were smart. While they did not make adornments, paint, or bury their dead, they made use of fire, and were handy with scrapers, anvils, points and assorted stone implements (Morwood \& van Oosterzee 2007:110).

The referees of the Nature papers agreed with Morwood, and in the published draft the creature was labelled Homo floresiensis. Where this leaves the Cerebral Rubicon, given that chimpanzees (approx. 400 c.c.) now qualify for human status,

\footnotetext{
${ }^{3}$ Woods and Collard's paper is recorded by the Web of Knowledge (http://wok.mimas.ac.uk/) to have been cited by 164 articles in the last eight years.
} 
is a matter for palaeoanthropologists, but here it serves the purpose of demonstrating that there is no hard, empirically-valid point at which the nonhuman becomes human. This is true not just for brain size, but any other feature one might wish to use:

In reality, many of these features evolved gradually, and at different rates, and it could not be expected that they evolved suddenly as a 'package'. Thus recognizing the first 'humans' is likely to remain a matter of great controversy, as it was for most of the last century (Stringer \& Andrews 2005:131).

Despite the fact that linking Homo and human makes palaeoanthropologists' jobs all the more difficult, the evidence from the case studies shows that they themselves have led the process. Although Morwood rues the difficulties brought by this conjoining, he uses Homo and human interchangeably in his discussion of LB1 (2007). He also cites Wood and Collard's paper 'The Human Genus' (1999), which sets out to clarify several explicit criteria upon which palaeoanthropologists might determine a potential Homo's inclusion or exclusion. Despite drawing attention to the complexities of categorising a figure as Homo, they notably use 'human' as interchangeable with 'Homo', as their title suggests. In the two papers that announced the discovery (Morwood et al 2004, Brown et al 2004), neither claims her as human, settling 
instead for Homo. However, the Nature press release for the discovery, which introduced journalists to the find, begins with the sentence:

The discovery of a new species of human living on the Indonesian island of Flores as recently as 18,000 years ago demonstrates that human diversity in the recent past was much greater than expected (2004:1).

All the press coverage followed this lead and was universal in labelling the find a human, as these opening lines from two newspapers demonstrate:

SCIENTISTS have discovered a previously unknown species of HUMANS who lived in a lost world stalked by giant rats and mutant elephants (The Sun 28.10.04).

When Indonesian and Australian archaeologists started to excavate a limestone cave on the Indonesian island of Flores, they weren't prepared for what they found, the skeleton of an entirely new species of human, Homo floresiensis, that lived as recently as 18,000 years ago (Guardian 28.10.04). 


\section{Linking to Pre-Existing Anchors}

Though both missing links considered here were declared human by scientists and journalists, there remained inescapable elements of otherness to them. These included their taxonomic positioning outside our species sapiens, their physical appearance as given by artists' reconstructions, and their limited capabilities. How then, could these creatures' status as human, but not human like us, be fixed? Pre-existing cultural figures that already inhabited a conceptually ambiguous status provide the solution. This is a further element in the process of anchoring, that helps secure a category’s position by tying it to others around it.

Unfortunately, the examples used to make sense of Piltdown's humanness were living indigenous tribes, or 'savages' as they were more likely to be labelled. There were two elements to this process. The first achieves its effect simply through the repeated comparison of Piltdown's primitive features with nonwhites. In Woodward's (1913) paper, he states that Piltdown's intermediate brain size "equals that of some of the lowest skulls of the existing Australians” (p126).

Similar claims pepper the news coverage. On the subject of Piltdown's canines (only uncovered later), the Illustrated London News states that they would have "an ape-like character met with in savage races to-day" (28.12.12:958). On the same page it offers up for comparison photos of three jaws, labeled "Kaffir", “Chimpanzee” and "Indian” respectively. Below it, another picture compares three more, with "Chimpanzee” and "European” either side of a suggested intermediary: “Torres Strait Islander”. Also in this article, a metaphor regarding 
the Piltdown eoliths adopts the same implicit message: "they speak as surely as did the footprints found by Robinson Crusoe.” The footprints in question were of course those of the black savage, who Robinson called "Man Friday". In this way another link is made between Piltdown and non-whites. Of the brain, the Express says: "as large as that of the lowest type of savage - the Australian aboriginal or the Tasmanians" (23.12.12:1) and similarly, from the Times, "the skull of Eoanthropus, though typically human, was as low in brain capacity as that of the lowest existing savages” (17.09.13:10). The Guardian quotes Keith as claiming, "in size of brain it is human - at least equal to the brains of many individuals in living races” (20.12.12:16).

The second element is more subtle but just as effective. Throughout the debate there is a continual conflation of the terms "species" and "race" such that they become indistinguishable. Stocking's (1994) work shows how "race” as a concept in the early $20^{\text {th }}$ century was often blurred with others such as "nation”. The effect achieved in the Piltdown case is that species becomes weakened as a divider and race becomes strengthened. The Express describes Piltdown as "a race of men who could not talk" (20.12.12:1) and mentions "the monkey race” (23.12.12:1). From the Illustrated London News we have this theme rendered explicitly, in a suggestion that Piltdown is no more different from modern Homo sapiens than we are from each other: 
these fragments of man from the Sussex gravel tell us that already at this early period the human race had begun to split up into different peoples (28.12.12:958).

The use of indigenous tribes in this way allows Piltdown's ape jaw and human skull to travel from the "doubtful borderland between recognisable man and indubitable ape” (Guardian 19.12.12:16) to become a human no more or less remote from white Europeans than an Aborigine. The fact that this process simultaneously moves non-whites away from us, at the same time that it moves Piltdown nearer, presumably only heightened its appeal amongst racist English scientists and journalists of the time.

In the Flores case, occurring almost a century after Piltdown, there was no such living human figure available - to try and claim any living Homo sapiens as examples of semi-humanness would be politically unacceptable. Instead, a figure was needed that existed outside the protections of our culturally and ethnically sensitive times. The answer: a fictional creation - the 'hobbit'. It provokes no political sensitivities and performs the role of the 'savage' perfectly - its anthropomorphic form brings it closer to us, whilst its diminutive dimensions and hirsuteness keep it distant.

Appearing originally in the fictional work of J.R.R. Tolkien, the hobbits were a diminutive sub-species of human. Despite the enduring popularity of Tolkien's 
work, it was Peter Jackson's Lord of the Rings films that cemented the Hobbit character widely within the contemporary consciousness. An often overlooked element of Tolkien's fantasy is its setting on our own Earth, deep within prehistory:

he did indeed create a new "mythology" (or at least mythical mode of thinking) not just suitable but deeply appealing for our time (Thomas 2006:83).

It is a pleasing reminder of how popular science blends fact and fiction that his work - creating an origins story suitable for contemporary interests - should be used to tell the tale of a missing link.

It certainly was used extensively - all seven of the UK newspapers included in our study adopted the hobbit label. Whilst it might be tempting to put the label's usage down to journalistic distortions of science, the reality is that the original connection was made by the scientists who discovered LB1. Peter Brown was against its use, but Morwood and the rest of the team had no such qualms:

As it transpired, the matter was out of Peter's hands; my younger Indonesian colleagues liked the name "Hobbit" and had begun to use it affectionately for LB1. "Hobbit” stuck (Morwood \& van Oosterzee 2007:153). 
This whole process of anchoring via affiliation is necessary because of the discrepancy between the flexible, multi-category scientific system of taxonomy, and the rigid, binary model of human-animal in popular culture. In this way, both missing links were anchored in the category 'human'. Yet whilst each of these structures, taxonomy and binary, differed in positioning of the anchor, each utilised a procedure of comparison to some pre-existing, ambiguous figure. The process of categorising the unfamiliar, of producing a social representation, whether within science or the media, was not as dissimilar as scientists might wish it to be. These exemplars of quasi-humanity, the savage and the Hobbit, enabled the rapid integration of the foreign physiognomic features of Piltdown and floresiensis whilst retaining some of their peregrinate nature. Both realms were prominently shaped by anthropocentricism and nationalism, the former directing the placement they were given, the latter some of the particular connections they made. The product was something like us, but not so much so as to be indistinguishable; related, but not familial; human, but not quite.

We now continue by discussing the process of objectifying our missing links, using as examples two narratives that emerged from the case studies.

\section{Objectifying Missing Links}

Whilst the scientific presentation of Piltdown proclaimed it human it did little to justify that decision and rather concerned itself with proxies of humanness 
such as brain size and speech capabilities. Scientists were happy to explicate Piltdown's humanness in the public realm however, where they provided some of the most sensationalist material, either directly, or in interview with journalists. This material relied far more upon preconceived folk knowledge than it did upon empirical, 'scientific' evidence. It is a similar conclusion that leads Haraway to state, "Scientific practice is above all a story-telling practice in the sense of historically specific practices of interpretation and testimony” (1989:4). The first coverage in the Guardian, a month prior to the official announcement, not only renders Piltdown a human, but creates a hunter narrative to put flesh on its bones:

It was the age when the cave bear, the woolly-haired rhinoceros, and the mammoth roamed over Europe, and man maintained a strenuous struggle for existence... Palaeolithic man was a river-draft hunter, and the Sussex skull was found in an old river bed. It is open to surmise that he met with his death while following his prey (Guardian 21.11.12:8).

Similar images appeared in coverage elsewhere:

Through the dark forests of our land there roamed, many hundreds of thousands of years ago, a strange, hairy ape-like creature, a female member ${ }^{4}$

\footnotetext{
${ }^{4}$ The 'female' reference follows a suggestion made by Woodward that Piltdown Man was actually Piltdown Woman. The other newspapers ignore this claim, but the Express makes great play of it, labelling the find 'The New Woman' - a barely veiled reference to the Suffragette movement that
} 
of a curious race, from whom all other animals shrank. She was a new type, possessing a new cunning, and an amazing power over the other denizens of the forest, for she could do what they could not - use implements, and clothe herself in skins... When she hunted she used no dogs to help her track her prey; she and her companions followed their quarry and killed it with a stone spear or hatchet (Express 23.12.12:1).

now a word or two as to his probable appearance and mode of life, and the creatures which he chased, and was occasionally, in turn, chased by. ... Elephants and rhinoceros of species long since extinct roamed in herds all round him. These and the hippopotamus no doubt he killed for food, and, besides, he must have hunted a species of horse long since extinct, while the lion, bear, and sabre-tooth tiger afforded him plenty of opportunities for hairbreadth escapes. He had probably inherited the use of fire from his forbears, and this useful ally served to harden the ends of his wooden spears, and perhaps to cook his food (Illustrated London News 28.12.12:958).

It might be argued that this is a media driven process to make the find humanrelevant, however Woodward himself is quoted in an Express article as being the source for a similar claim. It is clear this hunting narrative is not a journalistic

was demanding emancipation for women. The Express was highly critical of the Suffragettes, and sought to mock them by drawing parallels. See (Goulden 2007). 
distortion of the scientists' research, but rather a feature that is used by scientists and journalists alike to cement Piltdown's humanity. Woodward claims:

The thickness of the skull suggests outdoor life, and the teeth are ground down in a way that human teeth are not usually ground; they indicate a root and vegetable diet, mixed with dust and sand, accidentally introduced. The stone implements found by the skull were rude in design, and were employed in preparing skins, also in cutting wood. It is pretty certain that this was a race of wandering hunters. They had no domestic animals, for no bones of any have been found (in the Express 23.12.12:1).

Tellingly, Woodward presents the hunting narrative despite empirical evidence that seems quite contrary: 'they indicate a root and vegetable diet'. Similarly, in the Guardian article (21.11.12:8) man 'the river-draft hunter' is so because his skull is found in the river, and no consideration is given of other interpretations. In the Illustrated London News (28.12.12:958) Piltdown 'must' have hunted a species of horse, and 'no doubt' killed hippopotamus for food. This presupposition of a hunting lifestyle, "Man the Hunter”, colours the scenery in which man lives with a blood red hue.

Donna Haraway (1989) ascribes this Man the Hunter discourse, most popular in palaeoanthropology during the middle of the $20^{\text {th }}$ century, but present 
much earlier, to Western Cold-War scientists who created these proto-humans in their own image:

What it meant to be universal man and to be human generically turns out to look very much like what it meant to be western scientific men, especially in the United States, in the 1950s... Man the Hunter embodied a socially positioned code for deciphering what it meant to be human - in the western sense of unmarked, universal, species being - after World War II (pp.186187).

Pre-historical figures like Piltdown are receptive to such abstractions, and so are open to being shaped by cultural discourses, such as that of the heroic, technologically-enhanced hunter.

The Man the Hunter trope returns as a prominent repertoire with which Flores' human status is supported within popular culture. However, differences in the actual realisation of the Hunter template compared to the Piltdown case demonstrates clearly how it is flexible and open to adaptation, depending on the cultural mood of the time (Cartmill 1993). The imaginations of the creature's life resonate closely with those of Piltdown some ninety-eight years earlier, evidencing the common elements of hunting, technology, and terrifying beasts: 
On the island of Flores in the Malay Archipelago, scientists have found remains of a race of three-foot high humans who hunted pony-sized elephants and rats as big as dogs and who battled dragons with saliva laced with deadly bacteria. (Observer 31.10.04:21)

a previously unknown species of HUMANS who lived in a lost world stalked by giant rats and mutant elephants. (The Sun 28.10.04)

they used fire, made sophisticated stone tools, and hunted stegodon - a primitive type of elephant - and giant rats. (Daily Telegraph 28.10.04:01)

Just as Piltdown's life was narrated as a struggle against monsters given a semimythic quality by their absence from our contemporary world, Flores' existence is repeatedly built around bizarre adversaries - huge rats, tiny elephants, and “dragons" - i.e. large lizards related to the Komodo dragon. Despite these constants, there are deviations from the Man the Hunter template. These contemporary twists have at least two sources. The first of these is simply the particular physical characteristics of the discovery - Flores' diminutive stature provided a paradoxically vertiginous hurdle to clear for any scientist or journalist hoping to present the figure in the Mighty Hunter mould. Creating a three foot high fearsome warrior would be no mean feat. The mass media turns this 
challenge into an advantage however, and makes great play of contrasting Flores' stature with the fellow occupants of its island:

THE remains of a diminutive cousin of modern Man ..... Also known affectionately as "Flo", it hunted pygmy elephants the size of ponies and giant rats as large as golden retrievers, while trying to avoid huge Komodo dragons and other predatory lizards that are extinct. (Times 28.10.04:6).

A story of tiny Hobbit-like creatures battling giant, slavering dragons, of forest folk living in a tropical lost world, hunting miniature elephants and rats the size of retrievers (Daily Mail 28:10:04:24).

Other labels attached to the figure include 'mini-men' (ibid.), 'the height of a three-year-old child’ (Daily Telegraph 28:10:04:1), ‘toddler-sized human’ (ibid. 03.05.04:22), and 'no bigger than a dwarf' (The Express 28:10:04:17). The Times described the tools found in situ as 'toy-size' (28.10.04:6). The image created then is more 'Cute Hunter' than Mighty Hunter, perhaps demonstrated best by Australian artist Peter Schouten's iconic image of the creature shown below. Originally commissioned jointly by National Geographic and Morwood and Brown's team for the former's initial coverage, the image was widely reproduced in the mass media. Notably, although it features a weapon-wielding figure engaged in hunting - as in Forestier's Piltdown image (Illustrated London News 
28.12.12: iv,v) - the creature itself is markedly less imposing and is drawn posthunt, in a relatively relaxed state.

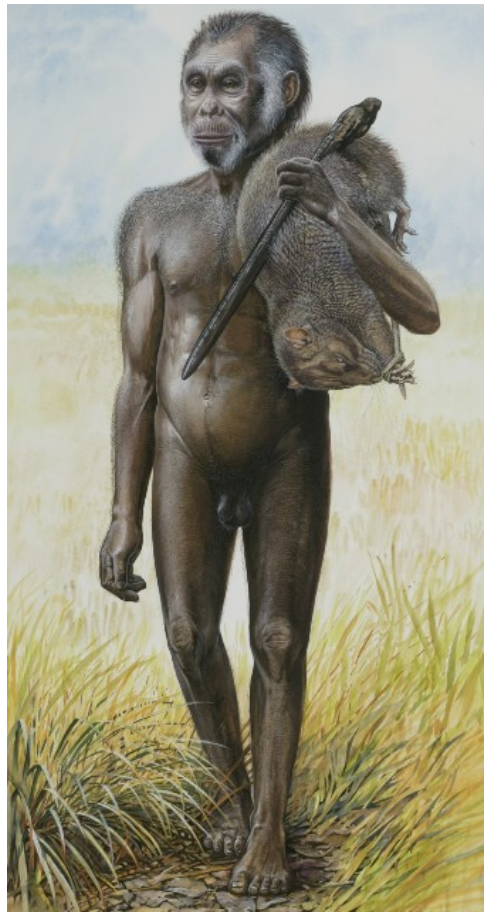

The Cute Hunter

Taken from www.studioschouten.com.au

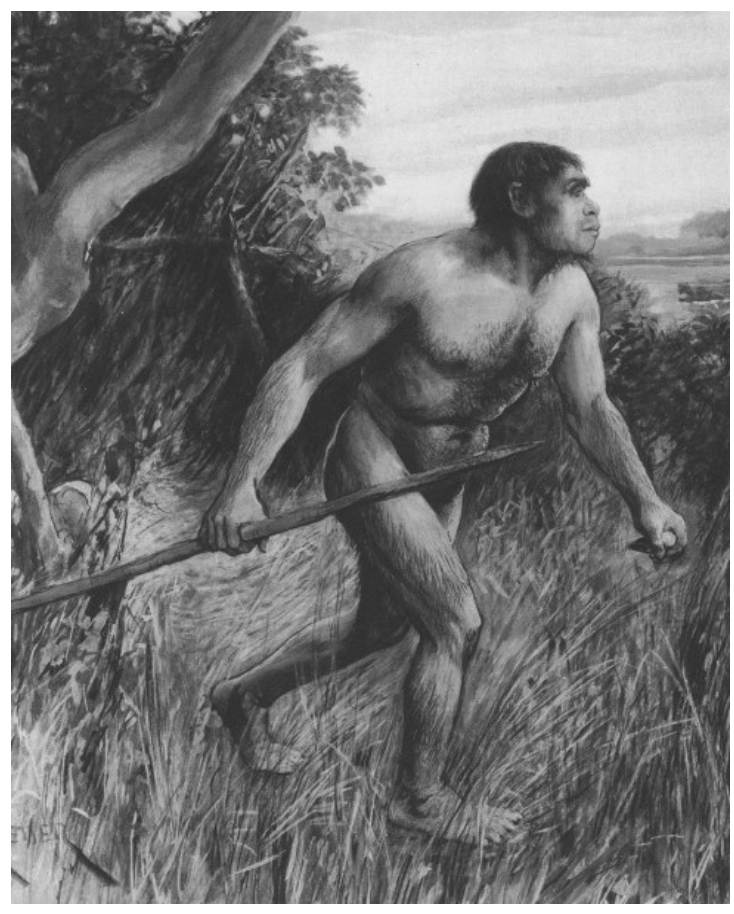

The Mighty Hunter

Taken from The Ill. London News 28.12.12

The grim determination on the face of Forestier's figure is replaced in Schouten's by a somewhat beatific grin. The sizeable spear carried by Piltdown dwarfs the small club held by Flores. Interestingly, although Brown et al's paper - like that of Dawson \& Woodward's - declares the skeleton to be most likely female, Schouten's Hunter - like that of Forestier's - is a male. This repetition also flags up a note of difference, one that purely reflects changing cultural tastes - although 
both figures appear naked, Piltdown Man's modesty is maintained by a strategically extended thigh. Flores Man apparently has no such qualms, and appears 'full-frontal'. However, in-keeping with the character's welcoming charm, the phallus itself is rather non-confrontational in appearance.

The second deviation from the Hunter template is more profound, and more telling of how reimaginings of these figures are structured by their particular socio-political context. In the twenty-first century version of the Hunter template, as expounded in the discourses around the Flores find, the killer has become us. The inspiration for this is the current of misanthropy within post-modernism that Franklin (1999) identifies in our changing relationship with animals. He states:

In the late twentieth century a generalized misanthropy has set in: according to this view humans are a destructive, pestilent species, mad and out of control. By contrast, animals are essentially good, balanced and sane (p.3).

Thus in LB1's media coverage, the Hunter is modern humans:

Many of these [species of hominin] may have been exterminated by Homo sapiens, which is also suspected of genocide in the demise of Homo erectus and Neanderthal Man (Times 28.10.04:6) 
And elsewhere:

[The division of human body lice into two species] could only have happened through some act of primal genocide when Homo erectus met Homo sapiens somewhere in eastern Siberia... the lice must have come from very fresh corpses and it is hard to suppose that they had died peacefully just before the intruders turned up (Guardian.co.uk 01.11.04).

This theme is further developed by imagining LB1's habitat as a tranquil paradise protecting its inhabitants from the threat of modern humans:

Their Eden remained undisturbed while modern humans colonised the world (Mirror 28.10.04:24).

We swept all before us. There was probably no deliberate conquest, just a steady outgunning by spear and arrow of precious resources from rival breeds.... safe in their lost world, the Hobbits lived on, undisturbed by the rise and rise of Homo sapiens (Daily Mail 28.10.04:25).

Thus, in the process of objectifying both figures there were prominent hunting narratives. These narratives connected with particular cultural mores specific to the figures' respective periods. Scientists themselves were highly 
active in this process, and in the case of Piltdown Man at least, they essentially created proto-man in their own image. For objectifying LB1, the hunter narrative remained, but was applied in a manner appropriate to the time. LB1 was not recreated as a Mighty Hunter, but a Cute Hunter. The feared killer became us, modern Homo sapiens, and not in a tone that was celebratory. In this way, both creatures were made meaningful for the society receiving them.

\section{Conclusion}

We set out in this chapter to analyse how the categorisation of missing links - hybrids of human and nonhuman animal - change as they move from within science outwards into the public realm. During this process the creatures are transferred from the box marked 'Homo' to the box marked 'human'. The reason for this recategorisation is twofold. First, scientific taxonomy has built into it a considerable flexibility that popular culture's dichotomous model of humananimal lacks. We saw this with our discussion of the 'Cerebral Rubicon', the classificatory line above which specimens become Homo. The regrading of this requirement, from 750 c.c. down to just 380 c.c., was not achieved without argument among scientists, but it did happen, in a relatively short 50 year time span. Popular culture's dichotomous model has remained unchanged for much longer, and is not controlled by a single, broadly homogenous community, as taxonomy is. As such it is exceedingly resistant to reconfiguration. Homo's flexibility means that it can formally incorporate chimeric figures with which the popular human-animal binary struggles. Scientists have the opportunity to simply 
create a new sub-category when they come across an ambiguous find - hence Homo floresiensis and Eoanthropus dawsoni.

The second reason is more pragmatic. Homo is a category of science, and as such has far less meaning, whether emotional or intellectual, for the general public than does the category human. It was in the interest of scientists and journalists alike to declare both finds human, as this ensured a greater public readership than would otherwise be the case. With public interest comes financial security, for both professions. The fact that the reconfiguration of missing links coincides with its transition from the science media to the news media may appear to implicate journalists alone. In considering the origins of particular claims we demonstrated that scientists themselves were heavily involved in the popularisation of Piltdown and LB1.

We charted the processes by which recategorisation is achieved through the utility of Moscovici's production of social representations via 'anchoring' and 'objectifying' knowledge. When the discoveries were moved into the popular realm their positional options were reduced to just two categories - human or animal. Human was chosen by scientists and journalists, for the pragmatic reason given above, and, in the case of Piltdown man at least, because nationalist sentiments amongst English stakeholders desired an ancient ancestor to which they could lay claim for the glory of the nation. Scientists and journalists anchored the figures by forcing them into the class human, even whilst acknowledging characteristics that seemed to preclude their entry. The instability of this 
positioning was fixed more firmly by linking to pre-existing figures who already occupied a tenuous position somewhere close to human, but not quite. Hence 'savages' and hobbits came to play a role in the process.

The fact that such ambiguous figures already exist raises the question of whether there really is a human-animal dichotomy within popular culture. We suggest that there is in fact another category, somewhere between human and animal, but one that only exists unconsciously. Bauman (1991) too describes these 'third categories', claiming they are an inevitable outcome of the non-fit between the contiguous natural world and the dichotomising human mind that seeks to understand it. When a case appears that does not concur with popular binaries the result is a third category that straddles the division. However, for Bauman, these third categories are a threat to the status quo, as they reveal the dichotomy for the sham it is:

"They are waste, as they defy classification and explode the tidiness of the grid. They are the disallowed mixture of categories that must not mix. They earned their death-sentence by resisting separation” (ibid. p15).

In our own work, this middle category, somewhere in the no man's land between human and animal, acts to protect the dichotomy by subsuming ambiguous figures. It is for this reason that Goulden labels these middle categories 'trinaries' a concept discussed in more detail elsewhere (Goulden 2007). 
The second part of this process of making the unfamiliar familiar, namely 'objectifying', consists of scientists and journalists creating a recognizable set of narratives around missing links, as a way of bringing meaning to their newly claimed humanness. 'Man the Hunter' discourses were present in the repertoires built around both Piltdown man and LB1; the different meanings invested in this trope reflect the fact that such stories are more a mirror of contemporary ideas than a window to the past. Regardless of specific meanings, why Man the Hunter featured in both cases is an interesting question. It may be that the discourse appeals to patriarchal western culture not only because of the militaristic/technological elements that Haraway (1989) identifies, but also because Man the Hunter echoes 'natural man', a man existing without culture. Marks (2003:166) notes the prominent role that such a figure played in the hugely influential works of Hobbes, Locke and Rousseau. Such figures offer a vision of life stripped bare of the complexities of modernity: existence at its most honest and brutal. Cartmill's analysis of hunting emphasises how the act is fundamentally an exploration of the boundary:

hunting takes place at the boundary between the human domain and the wilderness, the hunter stands with one foot on each side of the boundary, and swears no perpetual allegiance to either side. He is a liminal and ambiguous figure, who can be seen either as a fighter against wildness or as a half-animal participant in it (1996: 31). 
Perhaps then it is fitting that this repertoire should be used to bring to life missing links, since they too inhabit this borderland, swearing no perpetual allegiance to either side. And, in a more limited sense, it resembles the act of scientific categorisation itself, in which scientists occupy a liminal and ambiguous position between science and non-science culture, whilst struggling to impose order on disorder.

\section{References}

Bauman, Z. (1991) Modernity and Ambivalence. Oxford: Polity Press.

Brown et al (2004) 'A new small-bodied hominin from the Late Pleistocene of Flores, Indonesia’, Nature 431:1055-1061

Cassidy, A. (2005) 'Popular Evolutionary Psychology in the UK: An Unusual Case of Science in the Media?’, Public Understandings Of Science 14:115-141.

Cartmill, M. (1993) A View to a Death in the Morning. USA: Harvard University Press.

Dart, R. (1926) ‘Taung and Its Significance’, Natural History 26:315-327. 
Dart, R. (1957) 'The Osteodontokeratic Culture of Australopithecus Prometheus', Transvaal Museum Memoirs 10:1-105.

Dart, R. and Craig, D. (1959) Adventures with the Missing Link. New York: Harper.

Daston, L. and Mitman, G. (eds.) (2005) Thinking with Animals: New Perspectives on Anthropomorphism. USA: Columbia University Press.

Dawson, C. and Woodward, A.S. (1913) 'On the Discovery of a Paleolithic Human Skull and Mandible in a Flint-Bearing Gravel Overlying the Wealden (Hastings Beds) at Piltdown, Fletching (Sussex)', Quarterly Journal of the Geological Society of London 69:117-151.

Dupre, J. (2001) ‘In Defence of Classification’, Stud. Hist. Phil. Biol. \& Biomed. Sci., Vol. 32, No. 2, pp. 203-219.

Franklin, A. (1999) Animals and Modern Culture. Trowbridge: SAGE Publications. 
Guardian.co.uk (01.11.2004)

http://www.guardian.co.uk/news/2004/nov/01/wormseyeview. wrap

Goulden, M. (in press) 'Boundary-Work and the Human-Animal Boundary: Piltdown Man, Science and the Media’, Public Understandings of Science.

Goulden, M. (2007) 'Bringing Bones to Life: How Science Made Piltdown Man Human', Science as Culture 16:4 pp. 333 - 357.

Haraway, D. (1989) Primate Visions: Gender, Race, and Nature in the World of Modern Science. USA: Routledge.

Hrdlicka, A. (1922) 'The Piltdown Jaw', American Journal of Physical Anthropology 5:327-347.

Keith, A., Sir. (1949) A New Theory of Human Evolution. New York: Philosophical Library.

Krantz, G.S. (1961) 'Pithecanthropine Brain Size and Its Cultural Consequences’, Man 102 (May): 85-87. 
Latour, B. (1993) We Have Never Been Modern. Hemel Hempstead: Harvester Wheatsheaf.

Leakey, L.S.B., Tobias, P. V., and Napier, J. R. (1964) 'A New Species of The Genus Homo From Olduvai Gorge’, Nature 202 (4927): 7-9.

Lievrouw, L. (1990) 'Communication and the Social Representation of Scientific Knowledge’, Critical Studies in Mass Communication 7 (1): 1-10.

MacCurdy, G.G. (1916) 'The Revision of Eoanthropus Dawsoni', Science $43: 228-231$.

Marks, J. (2003) What it Means to be 98\% Chimpanzee. USA: University of California Press.

Miller, G.S. (1915) 'The Jaw of Piltdown Man’, Smithsonian Miscellaneous Collection 65:1-31.

Miller, G.S. (1918) 'The Piltdown Jaw', American Journal of Physical Anthropology 1:25-52. 
Morwood et al (2004) 'Archaeology and Age of a New Hominin from Flores in Eastern Indonesia’, Nature 431:1087-1091.

Morwood, M.J. and van Oosterzee, P. (2007) The discovery of the Hobbit: the scientific breakthrough that changed the face of human history. Sydney: Random House.

Moscovici, S. (1961). 'La psychanalyse, son image et son public', Paris: Presses Universitaires de France.

Moscovici, S. (1998). 'The History and Actuality of Social Representations' p209-248 in (eds.) Uwe Flick The Psychology of the Social Cambridge: Cambridge University Press .

Stringer, C. and Andrews, P. (2005) The Complete World of Human Evolution. Thames \& Hudson Ltd: China.

Stocking, G.W. (1994) 'The Turn-of-the-Century Concept of Race', Modernism/Modernity 1.1:4-16.

Thomas, K. (1996) Man and the Natural World. Oxford: Oxford University Press. 
Thomas, P.E. (2006) in Hammon, W.G. \& Scull, C (eds) The Lord of the Rings 1954-2004: Scholarship in Honor of Richard E. Blackwelder. Marquette University Press: USA.

Weidenreich, F. (1943) 'The skull of Sinanthropus pekinensis: a comparative study of a primitive hominid skull', Palaeontologica. Sinica New Series D. no. 10 Whole Series no. $127: 1-162$.

Wood, B and Collard, M. (1999) 'The Human Genus’, Science 284 (2): 65-71 . 